\title{
Characterisation of Subfractions of Asphaltenes Extracted from an Oil Sand using NMR, DEPT and MALDI-TOF
}

.

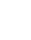

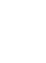

8
9 0 1 2 13 5 16 17 8 9 0 1 2 3

* Corresponding author:

Dr Mingming Zhu

Email: mingming.zhu@uwa.edu.au

7 Phone: +61 864885528

Fax: $\quad+61864887622$ 
31

32

33

34

35

36

37

38

39

40

41

42

43

44

45

46

47

48

49

50 51

\section{Abstract}

This paper reports the findings of an investigation into molecular structures and properties of an oil sand asphaltene sample and its subfractions. The asphaltene sample extracted from Buton Oil Sand (Indonesia) was fractionated stepwise into four subfractions by precipitation in a binary solvent system made from mixtures of dichloromethane/n-heptane with volumetric ratios of 30/70, 20/80 and 10/90, respectively. The average molecular structural parameters, including the average polycyclic aromatic hydrocarbon size, average side chain length and average molecular weight of the oil sand asphaltene sample and its subfractions, were measured and compared, using characterisation data obtained from nuclear magnetic resonance in combination with distortionless enhancement by polarisation transfer. The molecular weight distributions of the asphaltene samples were measured using a matrix-assisted laser desorption/ionisation time-of-flight mass spectrometry. The results indicated that the island molecular architecture was featured in all the asphaltene samples. The average polycyclic aromatic hydrocarbon size was found to be 7 rings for the least soluble subfraction, 6 rings for the other subfractions and the oil sand asphaltenes. The fractionation mechanism was dictated by polarity difference amongst subfractions as a result of relative luxuriance of the aliphatic parts. The use of ${ }^{13} \mathrm{C}$ NMR, DEPT and MALDI-TOF was shown to provide a useful means for characterisation and estimation of molecular structures of the asphaltenes.

Keywords: Asphaltenes; DEPT; Molecular structure; NMR; Oil sand; Fractions 


\section{Introduction}

In dealing with heavy petroleum resources, asphaltenes are the most refractory compounds among all the petroleum fractions that often lead to many operational challenges from extraction to refining, exemplified by reservoir damage, well plugging, pipeline blockage, sediment formation in tanks and tankers and, during refining and processing, catalyst deactivation, reactor failure and plant outage (Ancheyta et al., 2010; Mullins, 2007). Although there has been a remarkable progress in the continuing effort to understand the fundamental properties of asphaltenes (Mullins, 2010, 2011; Mullins et al., 2012), the level of knowledge about the molecular structures of asphaltenes is still in a nascent stage. In the meantime, oil sand, also known as tar sand or bituminous sand, is an unconventional resource of liquid hydrocarbons that has received less attention. The bitumen extracted from oil sand is very viscous and sticky because of its high content of asphaltenes. While extensive studies have been carried out on petroleum asphaltenes and coal-derived asphaltenes (Andrews et al., 2011; Artok et al., 1999; Begon et al., 2003; Christopher et al., 1996; Clutter et al., 1972; Dickinson, 1980; Fergoug and Bouhadda, 2014; Kaminski et al., 2000; Masuda et al., 1996; Michon et al., 1997; Sanchez-Minero et al., 2013; Sheremata et al., 2004; Snape et al., 1979; Tojima et al., 1998; Trejo et al., 2007; Trejo et al., 2004), more effort has been called for in order to understand the chemical structures of asphaltenes in oil sand.

As a complex mixture, the polydispersity of asphaltenes has greatly hampered the progress of its characterisation studies. A great deal of work has been conducted on fractionation of asphaltenes in the past (Andersen et al., 1997; Andreatta et al., 2005; Buch et al., 2003; Buenrostro-Gonzalez et al., 2002; Dickie and Yen, 1967; Groenzin et al., 2003; Jacobs and Filby, 1983; Kaminski et al., 2000; Nalwaya et al., 1999; Ovalles et al., 2012; Petrova et al., 2013; Tojima et al., 1998; Trejo et al., 2004; Wiehe and Liang, 1996; Yang and Eser, 1999). In the literature, binary solvent systems are commonly used to fractionate asphaltenes. Tojima et al. (1998) used a toluene/heptane system to fractionate asphaltenes into heavy and light subfractions. In their findings, the least soluble subfraction defined as heavy asphaltenes, consisted of the most highly condensed polycyclic 
aromatic hydrocarbons (PAHs) in the asphaltenes. Trejo et al. (2004) used the same binary solvent system to fractionate asphaltenes and compared the elemental composition across different fractions. Kaminski et al. (2000) reported fractionation work using a dichloromethane (DCM)/npentane system, in which the asphaltenes were firstly dissolved in DCM and then precipitated stepwise by adding increasing amounts of $n$-pentane. The precipitates were collected as subfractions by filtration when the DCM-to-n-pentane volumetric ratio reaching 30/70, 25/75, 20/80 and 10/90, respectively. Their results showed that the most polar subfraction (30/70) was not as soluble as the least polar subfraction (10/90). In addition, they also reported that unfractionated asphaltene samples appear to behave as a sum of their subfractions.

Many previous reports have discussed the trends amongst subfractions when using similar binary solvent systems, for example aromaticity was found to monotonically increase across subfractions with decreasing solubility and H/C ratio (Buch et al., 2003; Buenrostro-Gonzalez et al., 2002; Jacobs and Filby, 1983; Kaminski et al., 2000; Ovalles et al., 2012; Petrova et al., 2013; Tojima et al., 1998; Trejo et al., 2004; Yang and Eser, 1999). However effort to compare the subfractions in terms of their structural differences and use this approach to further probe the fractionation/precipitation mechanisms are scarce.

Among the spectroscopic techniques applied in characterising complex compounds, nuclear magnetic resonance (NMR) has been shown to have the potential for revealing the chemical nature of asphaltenes. Clutter and co-workers (1972) developed a technical method and protocol to characterise petroleum fractions with ${ }^{1} \mathrm{H}$ and ${ }^{13} \mathrm{C}$ NMR. They examined "aromaticity" through measuring aromatic carbon as a fraction of the total carbon, and brought forward a series of structural parameters, such as average number of aromatic rings and average number of alkyl substituents of an "average molecule”. Snape and Ladner (1979) compiled a survey of ${ }^{13} \mathrm{C}$ chemical shift in aromatic hydrocarbons in coal-derived materials. Since then a large body of literature on asphaltene molecular parameters using ${ }^{13} \mathrm{C}$ NMR has been reported (Artok et al., 1999; Begon et al., 2003; Buenrostro-Gonzalez et al., 2001; Calemma et al., 1995; Christopher et al., 1996; Dickinson, 
1980; Fergoug and Bouhadda, 2014; Gillet et al., 1980; Korb et al., 2013; Masuda et al., 1996; Michon et al., 1997; Myhr et al., 1990; Netzel, 1987; Ostlund et al., 2004; Rafenomanantsoa et al., 1994; Sanchez-Minero et al., 2013; Sheremata et al., 2004; Storm et al., 1994; Trejo et al., 2007; Yoshida et al., 1980). Likewise, since its introduction in 1988, laser desorption ionisation mass spectrometry has been increasingly used in the study of heavy fractions of petroleum (Karas and Hillenkamp, 1988). Because this technique tends to use a laser intensity that is low enough to vaporise the compounds without breaking their covalent bounds, it is considered a "soft" mass spectrometric technique. Since the method is also used to analyse compounds that display low light absorption and therefore require the addition of a laser-absorbing matrix, it is often known as the matrix-assisted laser desorption ionisation (MALDI) mass spectrometry. In practice, for high laserabsorbing samples such as asphaltenes, matrices are found not to be necessary (Acevedo et al., 2005; Apicella et al., 2007; Martínez-Haya et al., 2007; Pantoja et al., 2013; Rizzi et al., 2006; Tanaka et al., 2004).

In the present contribution, asphaltenes extracted from an oil sand sample was fractionated using a binary solvent system. The chemical structures of the asphaltene sample, together with its four subfractions, were studied using ${ }^{13} \mathrm{C}$ NMR in combination with DEPT-135, a method reported in our previous work (Zheng et al., 2017). A set of average structural parameters, such as average polycyclic aromatic hydrocarbon (PAH) size, average side chain length and average molecular weight (AMW), were calculated based on the NMR and DEPT results. MALDI-TOF was also employed to measure the molecular weight distributions (MWDs) of the asphaltene sample and its subfractions, in order to assist the interpretation of the ${ }^{13} \mathrm{C}$ NMR spectra. It was expected that the combined use of the three techniques would provide further insights into the understanding of the structural differences of the subfractions and shed new light on the fractionation mechanisms of the asphaltenes in the binary solvent system. 


\section{Experimental}

\subsection{Materials and sample preparation}

The asphaltene sample was extracted from Buton Oil Sand from Indonesia. The "run of mine” oil sand was crushed and pulverised into fine powders with sizes $<200 \mu \mathrm{m}$. The crushed sample was then subjected to solvent extraction using toluene in a Soxhlet extractor to obtain the organic fraction. The asphaltenes were isolated from the organic fraction in accordance with the method prescribed by the ASTM D-3279. Briefly, a sample of the organic fraction of the oil sand was firstly subjected to Soxhlet extraction using $n$-heptane as the solvent for at least 48 hours until no discoloration was observed in the reflux. The extraction was then continued by replacing $n$-heptane with toluene as the solvent for a further period of at least 8 hours till no further discoloration. The final extract was filtered, evaporated to dryness at $40^{\circ} \mathrm{C}$ using a rotary evaporator and further dried at $100^{\circ} \mathrm{C}$ under vacuum in an electric oven. The asphaltene sample thus prepared, denoted as Buton, was collected in clean glass vials, sealed and stored in darkness before further characterisation and analysis.

The Buton asphaltene was subjected to fractionation following a procedure as illustrated in Figure 1. Briefly, the asphaltene sample was initially dissolved in DCM and stirred for 2 hours. A solventto-sample ratio of 80:1 by weight was used, which had proven to be sufficient to fully dissolve the sample in preliminary filtration trials prior to this research. Subsequently, $n$-heptane was slowly added into the solution under stirring to form a binary solvent with a volumetric ratio of DCM/nheptane being 30/70. The mixture was left stirring for further 24 hours. The first fraction (F1), also known as the least soluble fraction, was recovered by filtering the mixture through Waterman GF/B glass microfiber filters, while the filtrate in the $\mathrm{DCM} / n$-heptane solvent was evaporated in a rotary evaporator to recover the soluble fraction. For the subsequent fractions, the same separation procedure was repeated except the ratio of the binary solvent was in turn changed to 20/80 and 10/90. The insoluble fractions isolated from $20 / 80$ and $10 / 90$ were denoted as the second fraction 
(F2) and the third fraction (F3), respectively. The soluble fraction from the last separation step was the most soluble fraction and was assigned as the fourth fraction (F4).

\subsection{Characterisation and Analysis}

The organic elemental compositions of the asphaltene sample and its fractions were acquired using a PerkinElmer 2400 Series II CHNS elemental analyser following ASTM D-5291. The analyses were repeated three times and the results are listed in Table 1.

The liquid ${ }^{13} \mathrm{C}$ NMR spectroscopy analyses were performed using a Varian 400 NMR spectrometer operating at $100.55 \mathrm{MHz}$. When preparing a sample for the NMR analysis, $80 \mathrm{mg}$ of each asphaltene sample was dissolved in $0.8 \mathrm{ml}$ of Deuterated chloroform $\left(\mathrm{CDCl}_{3}\right)$. Chromium acetylacetonate $\left(\mathrm{Cr}(\mathrm{acac})_{3}\right)$ was added into the solution at a concentration of $0.01 \mathrm{M}$ to ensure complete nuclear magnetic moment relaxation between pulses. In order to obtain quantitative results of ${ }^{13} \mathrm{C}$ NMR, the inverse gated decoupling technique was applied to suppress the Nuclear Overhauser Effect (NOE). The spectra were collected with a $45^{\circ}$ flip angle, 1.05 seconds acquisition time, 6.50 seconds recycle delay, 24,510 $\mathrm{Hz}$ spectral width and 30,000 scans. $\mathrm{CDCl}_{3}$ peaks at $77.16 \mathrm{ppm}$ were employed as the reference.

The DEPT $135^{\circ}$ (DEPT-135) spectroscopy analyses were performed with the same samples and the same Varian 400 NMR spectrometer, but operated using the following parameters: a polarisation transfer delay corresponding to $\mathrm{J}=140 \mathrm{~Hz}$ and a relaxation delay of 6.50 seconds. To obtain sufficient signal-to-noise ratios, 7,500 scans were collected.

The MWDs of the asphaltene sample and the fractions were obtained using an Ultraflex III MALDI-TOF mass spectrometer (Bruker Daltonics, Bremen, Germany). Runs with/without a matrix were carried out in parallel to examine the effect of the matrix on the results. In the case of the matrix being employed, a solution of $90 \% \mathrm{v} / \mathrm{v}$ acetonitrile $(\mathrm{ACN})$ and $10 \% \mathrm{v} / \mathrm{v}$ saturated $\alpha$ cyano-4-hydroxycinnamic acid (CHCA) in TA90 solution (90\% ACN, 0.01\%TFA) were used as the matrix to disperse the asphaltene sample. For a typical run, $1 \mu 1$ of $0.01 \mathrm{mg} \cdot \mathrm{ml}^{-1}$ asphaltenes in a DCM solution was spotted on the plate. The sample was ionised in the positive ion mode. Spectra 
were collected in the reflector mode with laser intensity in the range of $20 \%-25 \%$ and upon accumulation of 1,000 shots. The detection range was from 0 to 4,000Da but the mass signals below $\mathrm{m} / \mathrm{z}=200$ were suppressed to eliminate the background noise.

\section{Results and Discussion}

\subsection{Fractionation Yield}

The yields and the elemental analysis results for the subfraction samples are shown in Table 1, together with the calculated $\mathrm{H} / \mathrm{C}$ ratios. The process loss was about $5 \%$ by weight, which was incurred during the recovery of F1. It was shown that oxygen enriched in the least soluble subfraction F1. The H/C ratios of the subfractions increased from F2 to F4, while which of F1 and Buton fell in between.

\subsection{Aromaticity}

An important structural parameter, the aromaticity $\left(f_{a r}\right)$ was determined using ${ }^{13} \mathrm{C}$ NMR. This parameter has been used widely in the literature (Fergoug and Bouhadda, 2014; Luo et al., 2010; Ostlund et al., 2004; Sanchez-Minero et al., 2013) to gauge the aromatic fraction. Figure 2 shows typical ${ }^{13} \mathrm{C}$ NMR spectra of Buton and its subfractions. The ${ }^{13} \mathrm{C}$ NMR spectra were separated into the aromatic region from 100 to $160 \mathrm{ppm}$ and the aliphatic region from 0 to $60 \mathrm{ppm}$. Based on this method, $f_{a}$ can be calculated from Dickinson’s equation (Dickinson, 1980; Knight, 1967):

$f_{a}=\frac{C_{a r}}{C_{a r}+C_{a l}}$

where $C_{a r}$ and $C_{a l}$ stand for the integrations of the aromatic region and the aliphatic region, respectively. The calculated $f_{a}$ values are listed in Table 2 .

As shown in Row 1 of Table 2, the aromaticity of Buton revealed as an average of the aromaticities of its four subfractions. The aromaticities of the subfractions followed an increasing order of F2 > F1 $>$ F3 $>$ F4, where the aromaticity of F1 (44.21) is similar to that of Buton (44.44). The H/C atomic ratios shown in Table 1 followed the same pattern. 


\subsection{Carbon types}

210 As shown in Figure 2, the ${ }^{13} \mathrm{C}$ NMR spectra suffered severe overlaps in both the aromatic and aliphatic regions. In order to distinguish the different types of carbon, DEPT-135 analyses were performed. Figure 3 shows the typical DEPT-135 spectra of the asphaltene samples and Figure 4 shows their corresponding spectra in the aliphatic region with a chemical shift from 0 ppm to 60 ppm. As commonly known (Doddrell et al., 1982), $\mathrm{CH}$ and $\mathrm{CH}_{3}$ peaks are shown facing upwards, in a direction opposite to that of the $\mathrm{CH}_{2}$ in a DEPT spectrum Which could be used to help resolve overlapping peaks in aliphatic region of ${ }^{13} \mathrm{C}$ NMR spectra (Michon et al., 1997). As shown in Figure 4, the assignments of the regions representing different aliphatic carbons were determined for aliphatic carbons are summarised in Table 3.

However, it was still difficult to resolve the broad peaks in the aromatic region (100 to $160 \mathrm{ppm}$ ), as both the DEPT-135 and ${ }^{13} \mathrm{C}$ NMR spectra suffered from the overlap of both protonated and bridgehead carbons as shown in Figures 2 and Figure 3. In literature reports, the chemical shift regions of bridgehead carbon region was assigned up to 137 ppm (Masuda et al., 1996; Michon et al., 1997; Rafenomanantsoa et al., 1994; Yoshida et al., 1980), as it was believed that hetero aromatic rings and hydroxyl group could push the chemical shift of some bridgehead carbon as far as $137 \mathrm{ppm}$ in spectra. Considering the relative rarity of hetero aromatic ring in asphaltenes, the upper limit of the bridgehead carbon region was assigned to 133 ppm as suggested by Artok el al (1999) and Andrews et al (2011). The signals of the protonated aromatic carbon appeared at the chemical shift ranging from 100 to 130 ppm, overlaying with the potential region of bridgehead carbon with the chemical shift ranging from 124 to 133 ppm. Some literature reports tend to simply define the two regions at a cut-off point of 126.5 ppm (Begon et al., 2003; Fergoug and Bouhadda, 2014; Masuda et al., 1996), that is, the chemical shift from 100 to 126.5 ppm was deemed to belong to the protonated aromatic carbon region and that from 126.5 to $133 \mathrm{ppm}$ was regarded as the 
bridgehead carbon region. This could be very biased and lead to a large deviation from the true composition of asphaltenes (Andrews et al., 2011).

In the present study, the method proposed by Andrews et al (2011) was adopted to determine the amount of protonated aromatic carbon using both DEPT-135 spectra and ${ }^{13} \mathrm{C}$ NMR spectra. Instead of using a cut-off point, the intensity of protonated aromatic carbon was mathematically determined and subtracted from the overlapping region. Briefly, the intensity ratio between paraffinic methyl carbon and protonated aromatic carbon in the DEPT spectrum, $\mathrm{CH}_{3 \%} / C_{p r \%}$ as shown in Table 3, was firstly obtained. In order to make sure $\mathrm{CH}_{3 \%} / C_{p r \%}$ is of quantitative significance, the ratio was further normalised considering the polarisation intensities for carbons with different number of protons attached, as described below (Friebolin and Becconsall, 1993):

CH: Signal Intensity $=\left[\gamma\left({ }^{1} H\right) / \gamma\left({ }^{13} C\right)\right] \sin \theta ;$

$\mathrm{CH}_{2}$ : Signal Intensity $=\left[\gamma\left({ }^{1} \mathrm{H}\right) / \gamma\left({ }^{13} \mathrm{C}\right)\right] \sin 2 \theta$;

\section{$\mathrm{CH}_{3}:$ Signal Intensity $=\left[3 \gamma\left({ }^{1} \mathrm{H}\right) / 4 \gamma\left({ }^{13} \mathrm{C}\right)\right](\sin \theta+\sin 3 \theta)$}

where $\gamma$ is the magnetogyric ratio of the nucleus and $\theta$ is the pulse angle. Then the $C_{3 \%} / C_{p r \%}$ ratio was applied to the ${ }^{13} \mathrm{C}$ NMR spectrum of the same sample to calculate the intensity of the protonated aromatic carbon in the overlapping region, using the intensity of paraffinic methyl carbon in the ${ }^{13} \mathrm{C}$ NMR spectrum. The assignments of the regions representing different aromatic carbons are also summarised in Table 3.

Based on the chemical shift regions defined in Table 3, the average percentages of various aliphatic carbon and aromatic carbon were calculated by integrating the corresponding peaks on the quantitative ${ }^{13} \mathrm{C}$ NMR spectra. The results are listed in Rows 2-11 of Table 2. It is evident that the

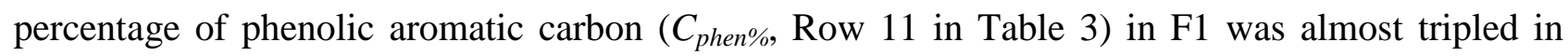
comparison to that of the other subfractions, which corresponded to a much higher oxygen content as shown in Table 1. 


\subsection{PAH size}

After subtracting the intensity of the protonated carbon in the overlapping region (100 to $133 \mathrm{ppm}$ ), the percentage $\left(X_{b}\right)$ of bridgehead carbon $\left(C_{b r \%}\right)$ to the total aromatic carbon $\left(C_{a r \%}\right)$ was obtained. In order to estimate the average size of the PAH cores, the theory developed by Solum et al. (1989) was espoused in the present work, which established the connection between $X_{b}$ and the number of aromatic carbon per PAH core $\left(C_{a r}\right)$, as represented by:

$X_{b}=\frac{1-\tanh \left(\frac{C_{a r}-C_{0}}{m}\right)}{2} X_{b}^{\prime}+\frac{1+\tanh \left(\frac{C_{a r}-C_{0}}{m}\right)}{2} X_{b}^{\prime \prime}$

where $C_{0}$ and $m$ are adjustable parameters to give the best fit of the dependence of $X_{b}$ on $C_{a r}$; optimal values of $C_{0}=19.57$ and $m=4.15$ were determined for all of the aromatic hydrocarbons projecting on to Coronene; $X_{b}^{\prime}\left(1 / 2-3 / C_{a r}\right)$ and $X_{b}^{\prime \prime}\left(1-\sqrt{6} / \sqrt{C_{a r}}\right)$ represent the molar fractions of the bridgehead carbon in catacondensation and in pericondensation (Solum et al., 1989).

The calculated $X_{b}$ and $C_{a r}$ values for Buton and its subfractions are listed in Row 12-13 of Table 3 . The $X_{b}$ values obtained for Buton and its subfractions were roughly the same, except which for F1, as shown in Row 12 of Table 3. The $C_{a r}$ obtained as shown in Row 13 of Table 3 showed that the differences among the subfractions were less than two carbons, indicating roughly the same average PAH size.

\subsection{Molecular architecture}

From the average numbers of aromatic carbon $\left(C_{a r}\right)$ estimated as shown in Row 13 of Table 2, an average PAH size of 5 or 6 rings was estimated for Buton and most of its subfractions (F2 to F4) depending on the type of condensation. The average PAH size for F1 could be 6 or 7 rings, slightly larger than those of the other fractions. In theory, the pericondensation is predominant when $X_{b}$ is larger than $0.49\left(C_{a r} \geq 24\right)$, while the catacondensation is the governing mechanism when $X_{b}$ is smaller than $0.29\left(C_{a r} \leq 14\right)$ (Solum et al., 1989). Considering asphaltenes are a group of different compounds containing PAH cores, the $C_{a r}$ values of 22 24 for Buton and its subfractions indicated that an overwhelming majority of the mixed compounds were in the form of pericondensation. Thus it is believed that an average of 6 fused rings PAH in F2 to F4, and possibly a larger PAH core with 
an average of 7 fused rings in F1 as a result of the two additional aromatic carbons. The average PAH size of Buton was, as a sum of its subfractions, 6 fused rings in the form of pericondensation. A great deal of literature publications have reported similar results on the molecular architecture of asphaltenes isolated from both coal and petroleum (Andrews et al., 2011; Groenzin and Mullins, 1999; Groenzin and Mullins, 2000, 2007, 2010; Mullins et al., 2012). However, the detailed PAH structures of asphaltenes are very complicated. There was a high level of heteroatoms such as oxygen and sulphur, in the asphaltenes, which could present in aromatic rings as furan and thiophene.

In order to further examine the average molecular architecture for the asphaltene samples, based on $C_{a r}, f_{a}$ and $C_{\text {sub\% }}$ (as defined in Table 3), the average number of aliphatic substitutions per PAH core $\left(n_{\text {sub }}\right)$ and the total number of the aliphatic and aromatic carbons $(C)$ were calculated using the following equations:

$n_{\text {sub }}=\left(C_{\text {sub\% }} / f_{a}\right) \times C_{a r}$

$C=C_{a r} / f_{a}$

Knowing $C$ and $n_{\text {sub }}$, the average number of aliphatic carbon per cluster $\left(C_{a l}\right)$ and the average carbon number per alkyl chain $(N)$ were calculated as follows:

$C_{a l}=\left(1-f_{a}\right) \times C$

$N=C_{a l} / n_{\text {sub }}$

The calculated results are listed in Rows 14-17 in Table 2.

It is noted that the average molecular parameters obtained from the NMR spectra followed a monotonic increasing or decreasing trend from F2 to F4. F1 was incongruous in the rows which will be discussed in the following paragraphs. From F2 to F4, the aliphatic parts became larger while the sizes of PAH cores stayed the same (Row 16 and Row 13 in Table 2) in an "average molecules", while the degree of aliphatic substitution on the PAH changed marginally (Row 14 in Table 2). As a result, the average chain length of the aliphatic substitution increased significantly from 2.90 to 3.96 as shown in Row 17 of Table 2. 
Hypothetically, the asphaltene molecules were attracted together as a result of $\pi-\pi$ stacking through the PAH cores while this attractive forces were offset by repulsive forces generated from the aliphatic substituents (Hashmi and Firoozabadi, 2013; Mullins, 2010; Mullins et al., 2012). The intermolecular forces amongst the asphaltene compounds in each fraction must be attractive and greater than the "pulling-apart” capability of the particular binary solvent system (Mullins, 2010). In other words, the fractionation of Buton in the $\mathrm{DCM} / n$-heptane binary solvent system was achieved by sorting the asphaltene molecules with different levels of "net intermolecular attractive force”. In the present study, the "net intermolecular attractive force" was found to be determined primarily by the luxuriance of the aliphatic part, as the PAH sizes were roughly the same across the subfractions.

As the least soluble fraction in this binary solvent system, F1 was expected to show the highest aromaticity, or in other words the highest "net intermolecular attractive force". However, the calculation results from NMR showed that F1 defied the trend observed in F2 to F4. It could be a result of the notably high heteroatom contents found in F1 as shown in Table 1. Sulphur and oxygen could potentially promote intermolecular bonding, which favoured aggregation (Foster, 1974; Murgich, 2002; Murgich et al., 1996) and therefore made some compounds precipitate in F1 with relatively lower aromaticity. More importantly, the compounds in F1 could be much more polarised than the ones in the other fractions due to the presence of some functional groups, such as hydroxyl, carboxylic and thiol. The presence of these functional groups would make the compounds too polar to stay in a nonpolar solvent, therefore precipitation happened as soon as $n$-heptane was added into the system. The high abundance of phenolic aromatic carbon in F1 as shown in Row 11 of Table 2 provided the evidence for the existence of hydroxyl groups. As these functional groups could be present in the asphaltene molecules with any type or size, the average molecular parameters of F1, not surprisingly, were similar to those of Buton as clearly shown in Table 2. It is believed that a portion of the compounds in F1 was precipitated following the "net intermolecular attractive force" theory as discussed previously, and consequently showing a relatively larger average PAH size and 
the shortest average substitution length; the other part of the compounds in F1 was precipitated due to the presence of polar functional groups, thus some of the average molecular parameters seemed "abnormal” in the group of subfractions. Leaving F1 aside, the average molecular parameters from F2 to F4 followed either an increasing or a decreasing pattern which was in consistence with the hypothesis of the "net intermolecular attractive force" theory.

Furthermore, there was a roughly $5 \mathrm{wt} \%$ loss during the fractionation process. It mainly happened during the course of recovering F1 from the glassfibre filter paper, as the isolated F1 did not completely dissolve back into the solution. In the solubility tests, the DCM solution with the same asphaltene concentration had left nothing on filters, which eliminates the possibility that asphaltenes were not fully dissolved at the very beginning. Other researchers have reported similar observations in the past (Andersen et al., 1997; Nalwaya et al., 1999), arguing that precipitation of asphaltenes was not a reversible process. Hirschberg et al. (1984) suggested that the process is reversible but very slow. In fact, even boiling toluene in which Buton was initially isolated, was not able to dissolve the insoluble residue on filter paper. This clearly indicated that the intermolecular forces had changed amongst those insoluble molecules, or micelles as some researcher reported (Andreatta et al., 2005). The hypothesis is that the fractionation process weakened the "peptising" or “facilitating” effect to those "heavy” molecules in F1, by removing the "light” molecules in F3 and F4. With the help of "light" molecules, DCM or toluene was able to keep the "heavy" molecules away from each other, thus stay in solution. The intermolecular interactions amongst the "heavy" molecules once formed are too strong for DCM, and thus the re-dissolution is impractical or at least very time-consuming. The $5 \mathrm{wt} \%$ loss may contain molecules with much higher aromaticity and would potentially be categorised as a part of F1 if they had been managed to re-dissolve in the solution.

\subsection{Molecular weight}


Based on the assumption that only one PAH core existed in each molecule (Groenzin and Mullins, 1999, 2000; Mullins, 2007, 2010, 2011; Sabbah et al., 2011), the numbers of other atoms, namely $\mathrm{H}, \mathrm{N}, \mathrm{S}$ and $\mathrm{O}$, were calculated according to the organic elemental analyses shown in Table 1 . The AMWs were computed as the sums of the atomic weights of all the elements in the given samples. The results are shown in Rows 18-22 of Table 2. In order to determine the number of PAH in an average asphaltene molecule and validate the AMWs calculated from the data derived from the NMR/DEPT spectra, the AMWs of Buton and its subfractions were calculated using MALDI-TOF. The typical MWDs of the samples measured using MALDI-TOF are shown in Figure 5. In consistence with the previous observations (Acevedo et al., 2005; Apicella et al., 2007; MartínezHaya et al., 2007; Pantoja et al., 2013; Rizzi et al., 2006; Tanaka et al., 2004), no difference was found between the spectra obtained with and without a matrix. The results presented here were therefore obtained without the use of a conventional matrix and based on the asphaltene own "selfmatrix" propensity. As shown in Figure 5, the samples had similar MWD profiles at the same intensity scale. It may be also seen that the majority of the detectable masses were present under the 1,500-m/z range, although there were "grass peaks" visible in the region up to 3,000m/z in F1 and F2.

The MWDs of the samples can provide information necessary to help with understanding of the architecture of the asphaltene molecules, such as the number of $\mathrm{PAH}$ in an average asphaltene molecule. Based on the MWDs of the samples, the AMW values may be derived from the following equation (Hurt et al., 2013):

$A M W=\frac{\sum\left[\left(\frac{m}{z}\right) \times A_{i}\right]}{\sum A_{i}}$

where $A_{i}$ stands for the intensity of the individual peaks $(1,2,3, \ldots, i)$ in the MWD spectrum, and $z$ is the charge. Since MALDI mainly generates single-charged species, $z$ is always equal to 1 in this case. Thus we use "Dalton (Da)", instead of “m/z", in the following elucidation.

From Equation (7), it is evident that the AMW calculation is dependent on the summation range. There were practically no peaks observed beyond the 3,000Da limit and hence the AMW values 
were calculated respectively in four summation ranges, namely 0-1,000Da, 0-1,500Da, 0-2,000Da and 0-3,000Da. The results are shown in Table 4, together with the AMW values derived from the NMR spectra for comparison.

The AMWs derived from MALDI-TOF revealed the same pattern as estimated from the NMR spectra. The AMWs deceased from F1 to F2 and then increased from F2 to F4 regardless of the summation range, except in the range 0-1,000Da where the AMWs constantly increased from F1 to F4 probably due to exclusion of some large molecules. Although the results in Table 4 become slightly larger as the summation range increases, each putative molecular weight in every range may only fit one PAH cluster. This confirms that each molecule contains only one PAH core, thus reassures the validity of the combined NMR/DEPT method in estimating the structural parameters of asphaltenes. In other words, the island molecular architecture is predominant in all the asphaltene samples studied. This is in consistence with previous studies of coal-derived and petroleum asphaltenes using various techniques such as time-resolved fluorescence depolarisation and twostep laser desorption ionisation (Groenzin and Mullins, 1999; Mullins, 2007, 2010; Sabbah et al., 2011).

\section{Conclusions}

In the present work, an oil sand asphaltene sample was fractionated into four subfractions using the DCM/n-heptane binary solvent system. The combination of NMR/DEPT and MALDI-TOF allowed the chemical structure of the oil sand and its subfractions to be revealed.

F1, the least soluble fraction, was found to contain an extremely high amount of oxygen. The average PAH size of F1 was about 7 fused rings in the form of pericondensation, while the other subfractions, F2 to F4, were found to contain an average $\mathrm{PAH}$ size of 6 rings dominated by pericondensation as well. The island architecture was shown to be predominant across the oil sand asphaltene sample and its subfractions. 
414 The AMWs of the samples were found to be $<1000$ Da. The AMW increased from F2 to F4, while 415 that of F1 fell in between. The precipitation mechanism was dictated by the compound polarity. The 416 most polar compounds precipitated in F1 while the remaining ones precipitated sequentially from 417 F2 to F4 according to relative "lushness" of their aliphatic parts. The average molecular parameters 418 of the oil sand asphaltene sample were shown to represent an average of its subfractions.

\section{Acknowledgement}

422 Partial financial support has been received from the Australian Research Council under the ARC 423 Discovery Projects (ARC DP160103636) and Linkage Projects Scheme (ARC LP100200135 and 424 ARC LP100200136). The authors acknowledge the access to the analytical and characterisation 425 facilities and associated scientific and technical assistance provided by the Australian Microscopy 426 and Microanalysis Research Facility at the Centre for Microscopy, Characterisation and Analysis, 427 The University of Western Australia (UWA), a facility funded by the University, State and 428 Commonwealth Governments. Ce Zheng also acknowledges the University Postgraduate Awards 429 scholarship provided by UWA. 


\section{References}

Acevedo, S., Gutierrez, L. B., Negrin, G., Pereira, J. C., Mendez, B., Delolme, F., Dessalces, G., Broseta, D. 2005. Molecular weight of petroleum asphaltenes: a comparison between mass spectrometry and vapor pressure osmometry. Energy Fuels 19(4), 1548-1560.

Ancheyta, J., Trejo, F., Rana, M. S. 2010. Asphaltenes: chemical transformation during hydroprocessing of heavy oils, CRC press.

Andersen, S. I., Keul, A., Stenby, E. 1997. Variation in composition of subfractions of petroleum asphaltenes. Pet. Sci. Technol. 15(7-8), 611-645.

Andreatta, G., Bostrom, N., Mullins, O. C. 2005. High-Q ultrasonic determination of the critical nanoaggregate concentration of asphaltenes and the critical micelle concentration of standard surfactants. Langmuir 21(7), 2728-2736.

Andrews, A. B., Edwards, J. C., Pomerantz, A. E., Mullins, O. C., Nordlund, D., Norinaga, K. 2011. Comparison of coal-derived and petroleum asphaltenes by ${ }^{13} \mathrm{C}$ nuclear magnetic resonance, DEPT, and XRS. Energy Fuels 25(7), 3068-3076.

Apicella, B., Carpentieri, A., Alfè, M., Barbella, R., Tregrossi, A., Pucci, P., Ciajolo, A. 2007. Mass spectrometric analysis of large $\mathrm{PAH}$ in a fuel-rich ethylene flame. Proc. Combust. Inst. 31(1), 547-553.

Artok, L., Su, Y., Hirose, Y., Hosokawa, M., Murata, S., Nomura, M. 1999. Structure and reactivity of petroleum-derived asphaltene. Energy \& Fuels 13(2), 287-296.

Begon, V., Suelves, I., Islas, C. A., Millan, M., Dubau, C., Lazaro, M. J., Law, R. V., Herod, A. A., Dugwell, D. R., Kandiyoti, R. 2003. Comparison of the quaternary aromatic carbon contents of a coal, a coal extract, and its hydrocracking products by NMR methods. Energy Fuels 17(6), 1616-1629.

Buch, L., Groenzin, H., Buenrostro-Gonzalez, E., Andersen, S. I., Lira-Galeana, C., Mullins, O. C. 2003. Molecular size of asphaltene fractions obtained from residuum hydrotreatment. Fuel 82(9), 1075-1084. 
Buenrostro-Gonzalez, E., Andersen, S. I., Garcia-Martinez, J. A., Lira-Galeana, C. 2002. Solubility/molecular structure relationships of asphaltenes in polar and nonpolar media. Energy Fuels 16(3), 732-741.

Buenrostro-Gonzalez, E., Groenzin, H., Lira-Galeana, C., Mullins, O. C. 2001. The overriding chemical principles that define asphaltenes. Energy Fuels 15(4), 972-978.

Calemma, V., Iwanski, P., Nali, M., Scotti, R., Montanari, L. 1995. Structural characterization of asphaltenes of different origins. Energy Fuels 9(2), 225-230.

Christopher, J., Sarpal, A. S., Kapur, G. S., Krishna, A., Tyagi, B. R., Jain, M. C., Jain, S. K., Bhatnagar, A. K. 1996. Chemical structure of bitumen-derived asphaltenes by nuclear magnetic resonance spectroscopy and X-ray diffractometry. Fuel 75(8), 999-1008.

Clutter, D. R., Petrakis, L., Stenger Jr, R. L., Jensen, R. K. 1972. Nuclear magnetic resonance spectrometry of petroleum fractions. Carbon-13 and proton nuclear magnetic resonance characterizations in terms of average molecule parameters. Anal. Chem. 44(8), 1395-1405.

Dickie, J. P., Yen, T. F. 1967. Macrostructures of the asphaltic fractions by various instrumental methods. Anal. Chem. 39(14), 1847-1852.

Dickinson, E. M. 1980. Structural comparison of petroleum fractions using proton and 13C nmr spectroscopy. Fuel 59(5), 290-294.

Doddrell, D. M., Pegg, D. T., Bendall, M. R. 1982. Distortionless enhancement of NMR signals by polarization transfer. J. Magn. Reson. 48(2), 323-327.

Fergoug, T., Bouhadda, Y. 2014. Determination of Hassi Messaoud asphaltene aromatic structure from ${ }^{1} \mathrm{H} \&{ }^{13} \mathrm{C}$ NMR analysis. Fuel 115(0), 521-526.

Foster, R. 1974. Organic charge transfer complexes, 1969. London, New York: Academic Press, R. Foster (ed.), Molecular Complexes 73, 1-2.

Friebolin, H., Becconsall, J. K. 1993. Basic one-and two-dimensional NMR spectroscopy, VCH Weinheim. 
Gillet, S., Delpuech, J., Valentin, P., Escalier, J. 1980. Optimum conditions for crude oil and petroleum product analysis by carbon-13 nuclear magnetic resonance spectrometry. Anal. Chem. 52(6), 813-817.

Groenzin, H., Mullins, O. C. 1999. Asphaltene molecular size and structure. J. Phys. Chem. A 103(50), 11237-11245.

Groenzin, H., Mullins, O. C. 2000. Molecular size and structure of asphaltenes from various sources. Energy Fuels 14(3), 677-684.

Groenzin, H., Mullins, O. C., Eser, S., Mathews, J., Yang, M.-G., Jones, D. 2003. Molecular size of asphaltene solubility fractions. Energy Fuels 17(2), 498-503.

Hashmi, S. M., Firoozabadi, A. 2013. Self-assembly of resins and asphaltenes facilitates asphaltene dissolution by an organic acid. J. Colloid Interface Sci. 394, 115-123.

Hirschberg, A., DeJong, L. N. J., Schipper, B. A., Meijer, J. G. 1984. Influence of temperature and pressure on asphaltene flocculation. Society of Petroleum Engineers Journal 24(03), 283293.

Hurt, M. R., Borton, D. J., Choi, H. J., Kenttämaa, H. I. 2013. Comparison of the structures of molecules in coal and petroleum asphaltenes by using mass spectrometry. Energy Fuels 27(7), 3653-3658.

Jacobs, F. S., Filby, R. H. 1983. Liquid chromatographic fractionation of oil-sand and crude oil asphaltenes. Fuel 62(10), 1186-1192.

Kaminski, T. J., Fogler, H. S., Wolf, N., Wattana, P., Mairal, A. 2000. Classification of asphaltenes via fractionation and the effect of heteroatom content on dissolution kinetics. Energy Fuels 14(1), 25-30.

Karas, M., Hillenkamp, F. 1988. Laser desorption ionization of proteins with molecular masses exceeding 10,000 daltons. Anal. Chem. 60(20), 2299-2301.

Knight, S. A., 1967. Analysis of aromatic petroleum fractions by means of absorption mode carbon13 NMR spectroscopy, Chem. Ind. 11, 1920-1923. 
Korb, J.-P., Louis-Joseph, A., Benamsili, L. 2013. Probing structure and dynamics of bulk and confined crude oils by multiscale NMR spectroscopy, diffusometry, and relaxometry. J. Phys. Chem. B 117(23), 7002-7014.

Luo, P., Wang, X., Gu, Y. 2010. Characterization of asphaltenes precipitated with three light alkanes under different experimental conditions. Fluid Phase Equilib. 291(2), 103-110.

Martínez-Haya, B., Hortal, A. R., Hurtado, P., Lobato, M. D., Pedrosa, J. M. 2007. Laser desorption/ionization determination of molecular weight distributions of polyaromatic carbonaceous compounds and their aggregates. J. Mass Spectrom. 42(6), 701-713.

Masuda, K., Okuma, O., Nishizawa, T., Kanaji, M., Matsumura, T. 1996. High-temperature NMR analysis of aromatic units in asphaltenes and preasphaltenes derived from Victorian brown coal. Fuel 75(3), 295-299.

Michon, L., Martin, D., Planche, J.-P., Hanquet, B. 1997. Estimation of average structural parameters of bitumens by ${ }^{13} \mathrm{C}$ nuclear magnetic resonance spectroscopy. Fuel 76(1), 9-15.

Mullins, O. C. 2010. The modified Yen model. Energy Fuels 24, 2179-2207.

Mullins, O. C. 2011. The asphaltenes. Annual Review of Anal. Chem., Vol 4. R. G. Cooks and E. S. Yeung. 4: 393-418.

Mullins, O. C., Eric Y.; Hammami, Ahmed; Marshall, Alan G; 2007. Asphaltenes, Heavy Oils, and Petroleomics, Springer, New York.

Mullins, O. C., Sabbah, H., Eyssautier, J., Pomerantz, A. E., Barre, L., Andrews, A. B., RuizMorales, Y., Mostowfi, F., McFarlane, R., Goual, L., Lepkowicz, R., Cooper, T., Orbulescu, J., Leblanc, R. M., Edwards, J., Zare, R. N. 2012. Advances in asphaltene science and the Yen-Mullins model. Energy Fuels 26(7), 3986-4003.

Murgich, J. 2002. Intermolecular forces in aggregates of asphaltenes and resins. Pet. Sci. Technol. 20(9-10), 983-997.

Murgich, J., Rodríguez, J., Aray, Y. 1996. Molecular recognition and molecular mechanics of micelles of some model asphaltenes and resins. Energy Fuels 10(1), 68-76. 
Myhr, M. B., Schou, L., Skjetne, T., Krane, J. 1990. Characterization of asphaltenes and coprecipitated material from a Californian crude oil. Org. Geochem. 16(4-6), 931-941.

Nalwaya, V., Tantayakom, V., Piumsomboon, P., Fogler, S. 1999. Studies on asphaltenes through analysis of polar fractions. Ind. Eng. Chem. Res. 38(3), 964-972.

Netzel, D. A. 1987. Quantitation of carbon types using DEPT/QUAT NMR pulse sequences: application to fossil-fuel-derived oils. Anal. Chem. 59(14), 1775-1779.

Ostlund, J. A., Wattana, P., Nyden, M., Fogler, H. S. 2004. Characterization of fractionated asphaltenes by UV-vis and NMR self-diffusion spectroscopy. J. Colloid Interface Sci. 271(2), 372-380.

Ovalles, C., Rogel, E., Moir, M., Thomas, L., Pradhan, A. 2012. Characterization of heavy crude oils, their fractions, and hydrovisbroken products by the asphaltene solubility fraction method. Energy Fuels 26(1), 549-556.

Pantoja, P. A., Mendes, M. A., Nascimento, C. A. O. 2013. Contribution of mass spectrometry in assessing quality of petroleum fractions: the use of mass spectrometry for assessing asphaltenes. J. Pet. Sci. Eng. 109(0), 198-205.

Petrova, L. M., Abbakumova, N. A., Zaidullin, I. M., Borisov, D. N. 2013. Polar-solvent fractionation of asphaltenes from heavy oil and their characterization. Petroleum Chemistry 53(2), 81-86.

Rafenomanantsoa, A., Nicole, D., Rubini, P., Lauer, J. C. 1994. Structural analysis by NMR and FIMS of the tar-sand bitumen of Bemolanga (Malagasy). Energy Fuels 8(3), 618-628.

Rizzi, A., Cosmina, P., Flego, C., Montanari, L., Seraglia, R., Traldi, P. 2006. Laser desorption/ionization techniques in the characterization of high molecular weight oil fractions. Part 1: asphaltenes. J. Mass Spectrom. 41(9), 1232-1241.

Sabbah, H., Morrow, A. L., Pomerantz, A. E., Zare, R. N. 2011. Evidence for island structures as the dominant architecture of asphaltenes. Energy Fuels 25(4), 1597-1604. 
Sanchez-Minero, F., Ancheyta, J., Silva-Oliver, G., Flores-Valle, S. 2013. Predicting SARA composition of crude oil by means of NMR. Fuel 110, 318-321.

Sheremata, J. M., Gray, M. R., Dettman, H. D., McCaffrey, W. C. 2004. Quantitative molecular representation and sequential optimization of Athabasca asphaltenes. Energy Fuels 18(5), 1377-1384.

Snape, C. E., Ladner, W. R., Bartle, K. D. 1979. Survey of carbon-13 chemical shifts in aromatic hydrocarbons and its application to coal-derived materials. Anal. Chem. 51(13), 2189-2198.

Solum, M. S., Pugmire, R. J., Grant, D. M. 1989. Carbon-13 solid-state NMR of Argonne-premium coals. Energy Fuels 3(2), 187-193.

Storm, D. A., Edwards, J. C., DeCanio, S. J., Sheu, E. Y. 1994. Molecular representations of Ratawi and Alaska North slope asphaltenes based on liquid-and solid-state NMR. Energy Fuels 8(3), 561-566.

Tanaka, R., Sato, S., Takanohashi, T., Hunt, J. E., Winans, R. E. 2004. Analysis of the molecular weight distribution of petroleum asphaltenes using laser desorption-mass spectrometry. Energy Fuels 18(5), 1405-1413.

Tojima, M., Suhara, S., Imamura, M., Furuta, A. 1998. Effect of heavy asphaltene on stability of residual oil. Catal. Today 43(3-4), 347-351.

Trejo, F., Ancheyta, J., Morgan, T. J., Herod, A. A., Kandiyoti, R. 2007. Characterization of asphaltenes from hydrotreated products by SEC, LDMS, MALDI, NMR, and XRD. Energy Fuels 21(4), 2121-2128.

Trejo, F., Centeno, G., Ancheyta, J. 2004. Precipitation, fractionation and characterization of asphaltenes from heavy and light crude oils. Fuel 83(16), 2169-2175.

Wiehe, I. A., Liang, K. S. 1996. Asphaltenes, resins, and other petroleum macromolecules. Fluid Phase Equilib. 117(1-2), 201-210.

Yang, M.-G., Eser, S. 1999. Fractionation and molecular analysis of a vacuum residue asphaltenes. Papers of the Amer. Chem. Soc. 218, 625. 
585 Yoshida, T., Maekawa, Y., Uchino, H., Yokoyama, S. 1980. Derivation of structural parameters for 586 coal-derived oil by carbon-13 nuclear magnetic resonance spectrometry. Anal. Chem. 52(6), $587 \quad 817-820$.

588 Zheng, C., Zhu, M., Zhou, W., Zhang, D. 2017. A preliminary investigation into the 589 characterization of asphaltenes extracted from an oil sand and two vacuum residues from 590 petroleum refining using nuclear magnetic resonance, DEPT, and MALDI-TOF. ASME J. $591 \quad$ Energy Resour. Technol. 139(3), 032905.

592

593

594

595

596

597

598

599

600

601

602

603

604

605

606

607

608

609

610 


\section{Figure Captions}

612 Figure 1 A schematic illustration of the fractionation procedure

613 Figure 2 Typical ${ }^{13} \mathrm{C}$ NMR spectra of Buton and its subfractions

614 Figure 3 DEPT-135 spectra of Buton and its subfractions

615 Figure 4 Subdivision of the aliphatic regions according to DEPT-135

616 Figure 5 MALDI-TOF spectra of Buton and its subfractions

617

618 
619 Figure 1

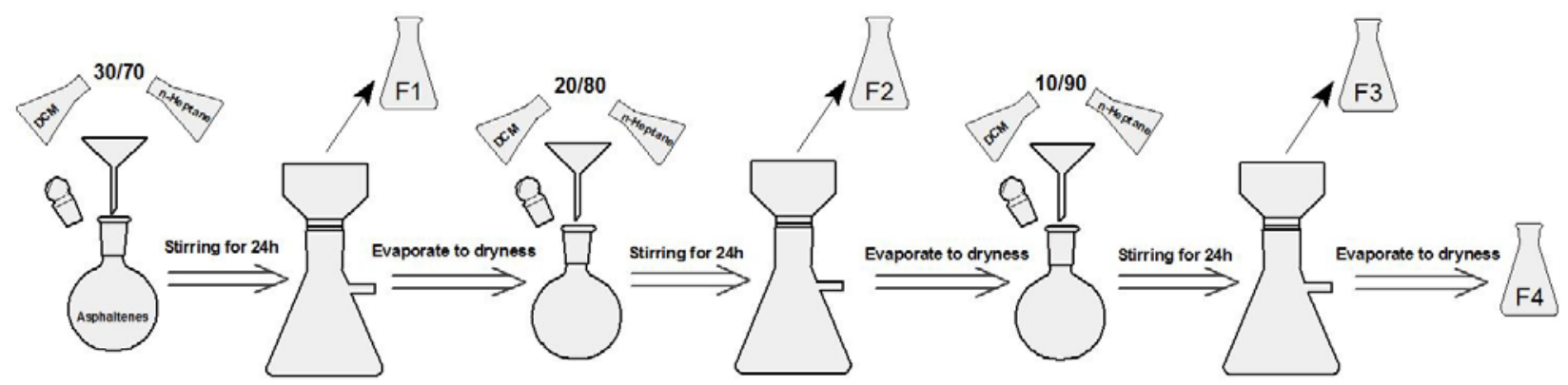

620

621 Figure 1 A schematic illustration of the fractionation procedure

622

623 
Figure 2

625

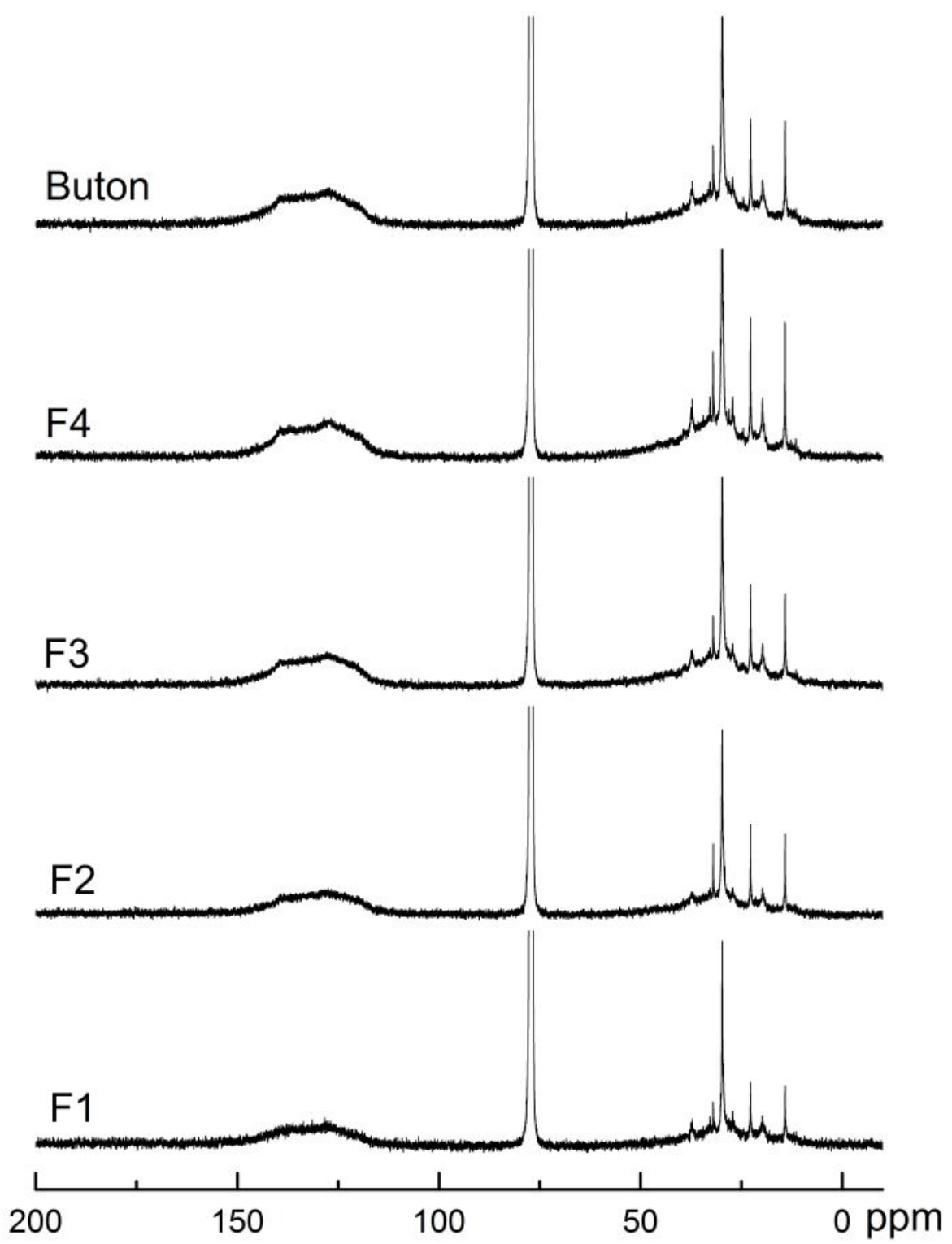

626 Figure 2 Typical ${ }^{13} \mathrm{C}$ NMR spectra of Buton and its subfractions

627

628 
629 Figure 3
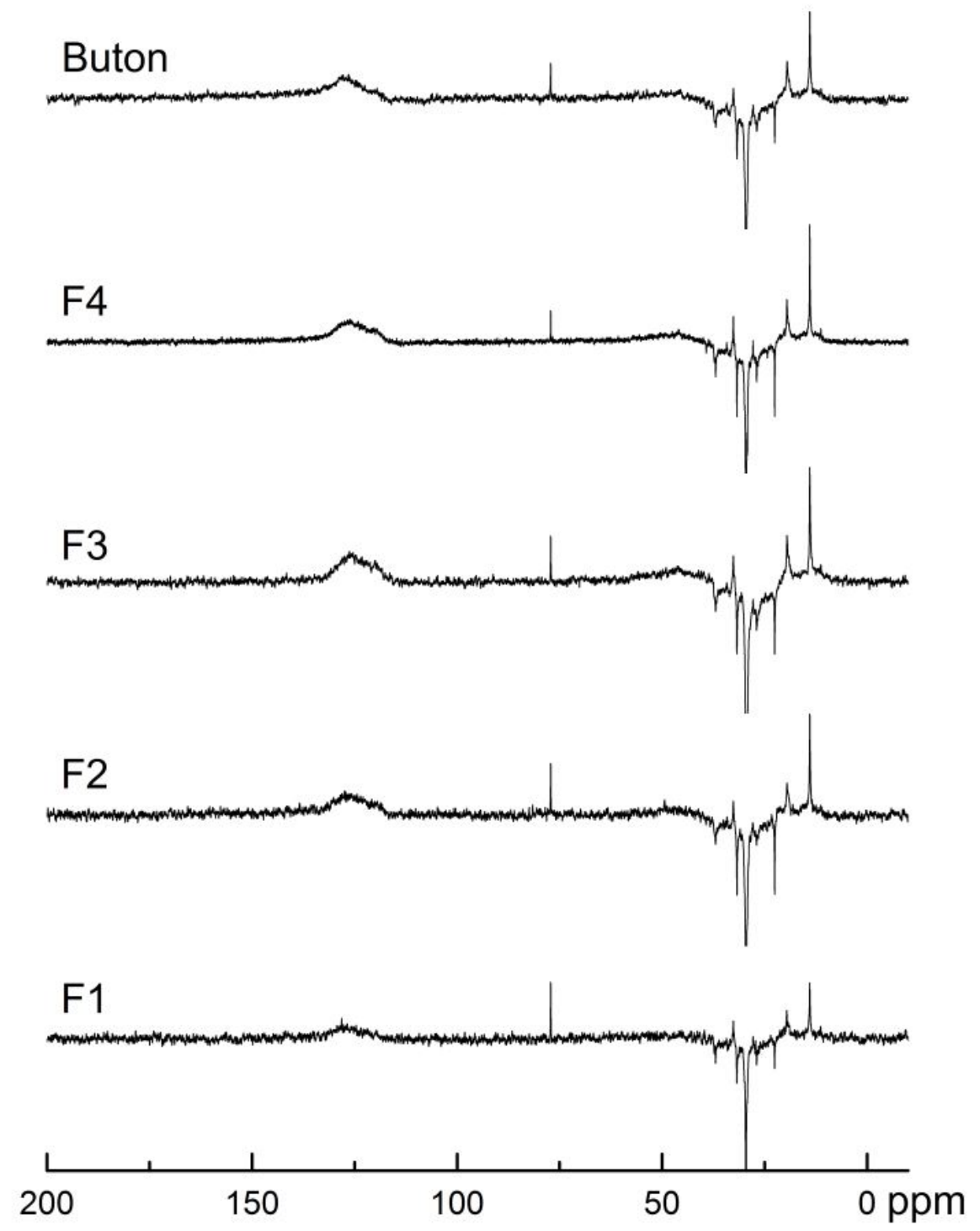

630

631 Figure 3 DEPT-135 spectra of Buton and its subfractions

632

633 


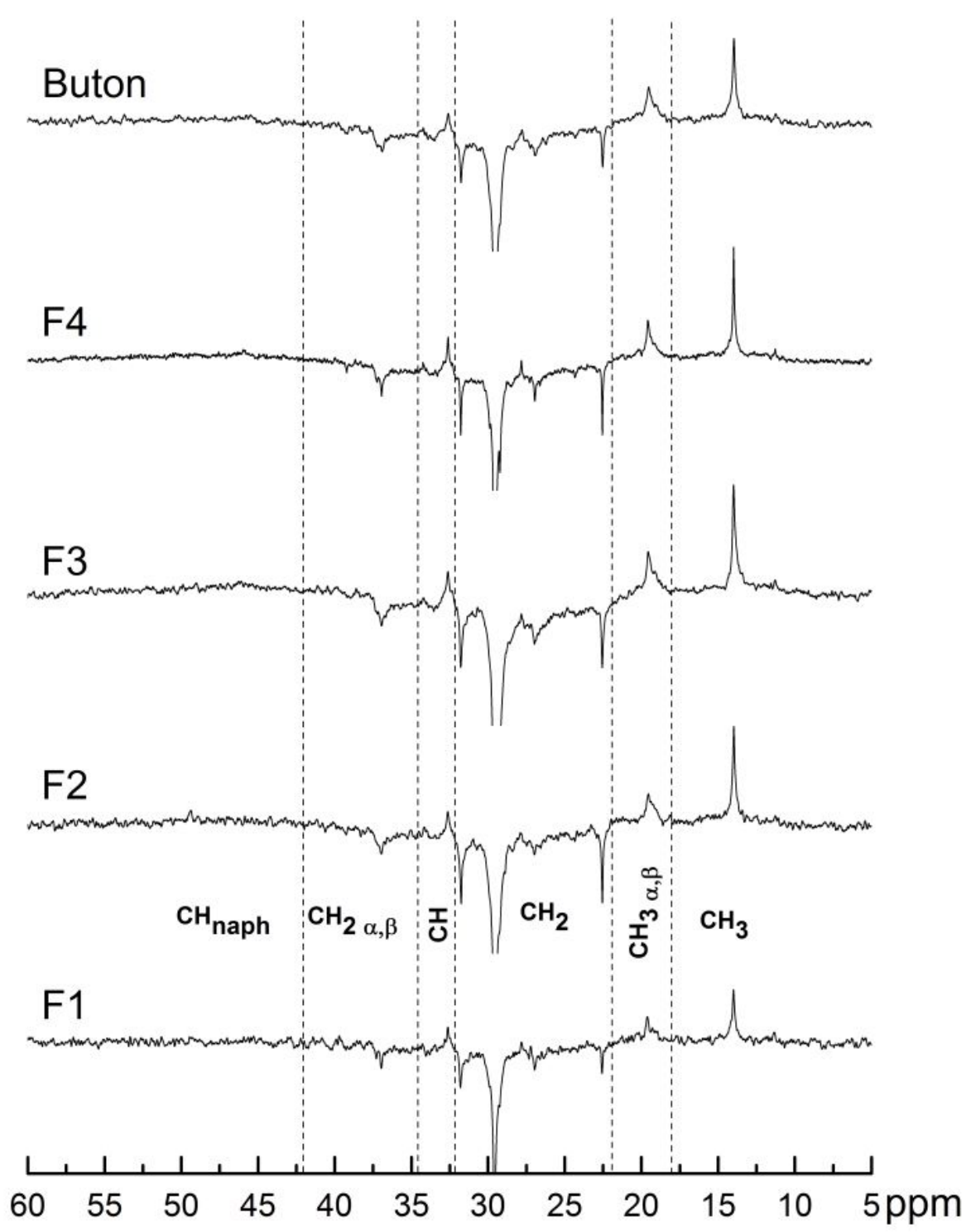

636 Figure 4 Subdivision of the aliphatic regions according to DEPT-135 
Figure 5

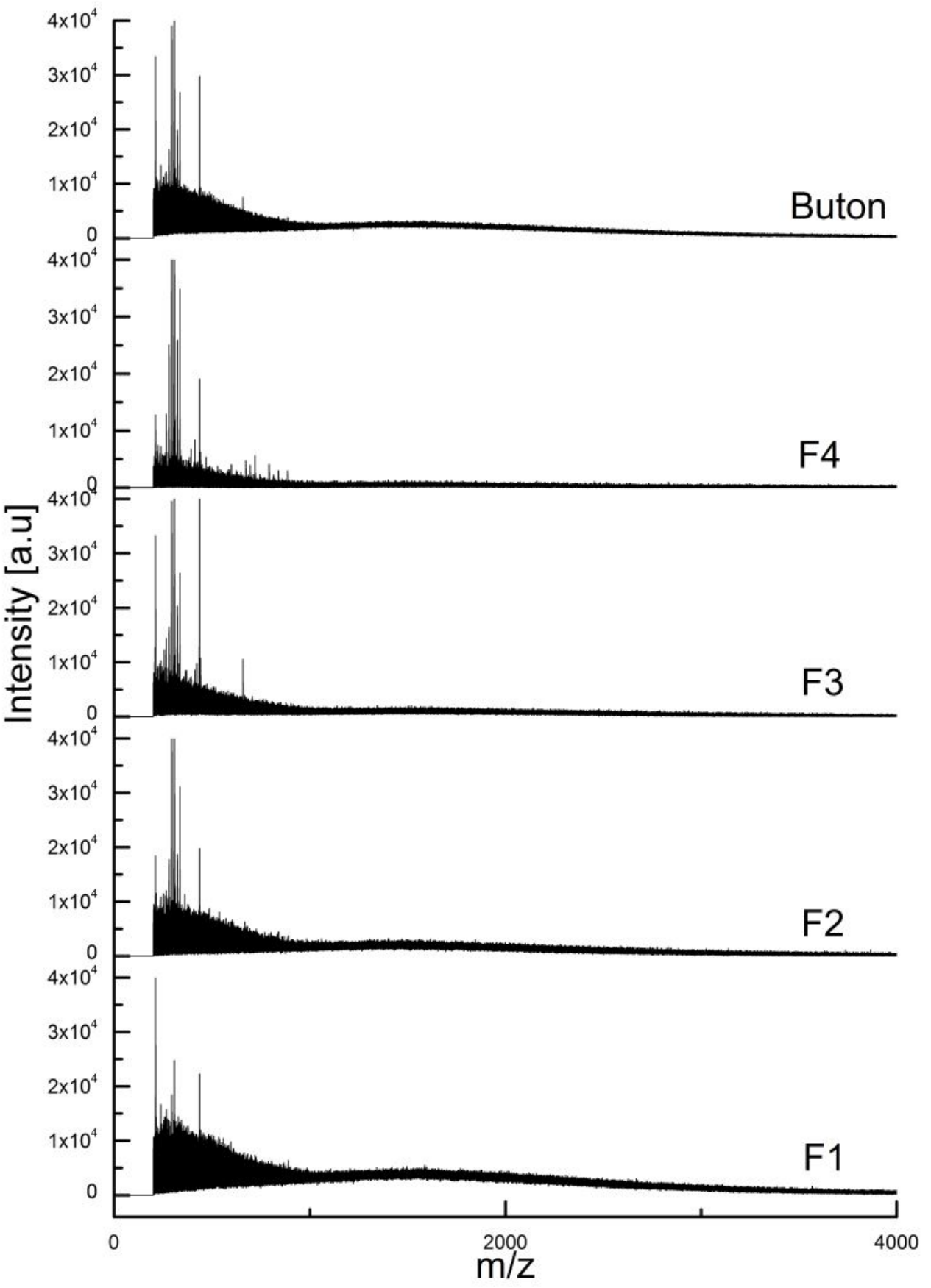

641 Figure 5 MALDI-TOF spectra of Buton and its subfractions 


\section{List of Tables}

645 Table 1 Yields of the subfractions and their elemental compositions

646 Table 2 Average structural parameters of Buton and its subfractions, calculated from ${ }^{13} \mathrm{C}$ NMR 647 and DEPT-135 spectra

648 Table $3{ }^{13} \mathrm{C}$ NMR chemical shift region assignments for the asphaltene samples

649 Table 4 AMWs estimated from MWDs using MALDI-TOF in different summation ranges and $650 \quad$ from ${ }^{13} \mathrm{C}$ NMR spectra

651

652 
653 Table 1 Yields of the subfractions and their elemental compositions

\begin{tabular}{ccccccc}
\hline & F1 & F2 & F3 & F4 & Buton & Loss \\
\hline Fractionation yield (wt\%) & & & & & & \\
& 28.56 & 12.42 & 20.08 & 33.92 & N/A & 5.02 \\
\hline Elemental composition (wt\%) & & & & & & \\
Carbon & 72.11 & 77.62 & 79.27 & 79.85 & 75.06 & N/A \\
Hydrogen & 8.57 & 9.02 & 9.50 & 10.02 & 8.87 & N/A \\
Nitrogen & 0.89 & 0.96 & 0.91 & 0.85 & 0.90 & N/A \\
Sulphur & 7.66 & 8.71 & 8.51 & 8.04 & 8.13 & N/A \\
Oxygen (by difference) & 10.77 & 3.69 & 1.81 & 1.24 & 7.04 & N/A \\
H/C atomic ratio & 1.43 & 1.39 & 1.44 & 1.51 & 1.42 & N/A \\
\hline
\end{tabular}

654

655

656 
657 Table 2 Average structural parameters of Buton and its subfractions, calculated from ${ }^{13} \mathrm{C}$ NMR 658 and DEPT-135 spectra

\begin{tabular}{|c|c|c|c|c|c|c|}
\hline Row & Average Molecular Parameters* & $\mathbf{F 1}$ & F2 & F3 & $\mathbf{F 4}$ & Buton \\
\hline 1 & Aromaticity from ${ }^{13} \mathrm{C} N M R\left(f_{a}\right) \%$ & 44.21 & 47.49 & 42.12 & 39.76 & 44.44 \\
\hline 2 & Terminal methyl group $\mathrm{CH}_{3 \%}$ & 7.68 & 4.85 & 6.90 & 5.59 & 6.25 \\
\hline 3 & Methyl group at $\alpha$ or $\beta$ position $\mathrm{CH}_{3 \alpha, \beta \%}$ & 6.09 & 4.68 & 5.27 & 5.07 & 5.35 \\
\hline 4 & Methylene group $\mathrm{CH}_{2 \%}$ & 28.22 & 25.51 & 25.65 & 27.00 & 26.17 \\
\hline 5 & Methine group $\mathrm{CH}_{\%}$ & 4.61 & 4.82 & 4.82 & 5.50 & 4.76 \\
\hline 6 & Methylene group at $\alpha$ or $\beta$ position $\mathrm{CH}_{2}$ & 7.64 & 9.16 & 9.33 & 10.76 & 9.06 \\
\hline 7 & Methine group in naphthenic rings & 0.52 & 3.49 & 5.91 & 6.32 & 3.98 \\
\hline 8 & Protonated/hetero aromatic $C_{p r \%}$ & 1.73 & 7.19 & 5.46 & 6.16 & 4.68 \\
\hline 9 & Bridgehead aromatic $C_{b r \%}$ & 21.44 & 21.42 & 19.08 & 17.97 & 20.13 \\
\hline 10 & Substituted aromatic $C_{s u b \%}$ & 20.23 & 18.08 & 16.88 & 15.21 & 18.40 \\
\hline 11 & Phenolic aromatic $C_{\text {phen\% }}$ & 1.84 & 0.79 & 0.69 & 0.42 & 1.23 \\
\hline 12 & Percentage of bridgehead carbon $X_{b}$ & 0.485 & 0.451 & 0.453 & 0.452 & 0.453 \\
\hline 13 & Average aromatic $P A H$ size $C_{a r}$ & 23.89 & 22.01 & 22.11 & 22.06 & 22.11 \\
\hline 14 & Substitutions per $P A H n_{\text {sub }}$ & 10.93 & 8.38 & 8.86 & 8.44 & 9.15 \\
\hline 15 & Molecular carbon atoms $* C$ & 54.04 & 46.35 & 52.49 & 55.48 & 49.75 \\
\hline 16 & Average number of aliphatic carbon $C_{a l}$ & 30.15 & 24.34 & 30.38 & 33.42 & 27.64 \\
\hline 17 & Average carbon number per alkyl chain & 2.76 & 2.90 & 3.43 & 3.96 & 3.02 \\
\hline 18 & Molecular hydrogen atoms* & 77.04 & 64.67 & 75.53 & 83.57 & 70.55 \\
\hline 19 & Molecular nitrogen atoms* & 0.57 & 0.49 & 0.52 & 0.51 & 0.51 \\
\hline 20 & Molecular sulphur atoms* & 2.15 & 1.95 & 2.11 & 2.10 & 2.02 \\
\hline 21 & Molecular oxygen atoms* & 6.05 & 1.65 & 0.90 & 0.65 & 3.50 \\
\hline 22 & Average molecular weight* & 899 & 717 & 795 & 834 & 795 \\
\hline
\end{tabular}




\begin{tabular}{|c|c|c|c|}
\hline \multicolumn{3}{|c|}{ Regions in ppm } & \multirow[t]{2}{*}{ Types of Carbons } \\
\hline \multirow[t]{7}{*}{ Aliphatic } & $5.0-60.0$ & $C_{a l}$ & \\
\hline & $5.0-18.0$ & $\mathrm{CH}_{3}$ & $\begin{array}{l}\text { Terminal or branched methyl groups in aliphatic chains, } \\
\text { except where branched at } \alpha \text { or } \beta \text { position from an } \\
\text { aromatic ring or where two methyl groups are terminal }\end{array}$ \\
\hline & $18.0-22.0$ & $\mathrm{CH}_{3 \alpha, \beta}$ & $\begin{array}{l}\text { Methyl groups in aliphatic chains branched at } \alpha \text { or } \beta \\
\text { position from an aromatic ring, plus where two methyl } \\
\text { groups are terminal }\end{array}$ \\
\hline & $22.0-32.0$ & $\mathrm{CH}_{2}$ & $\begin{array}{l}\text { Methylene groups in aliphatic chains and in naphthenic } \\
\text { rings, except where branched at } \alpha \text { or } \beta \text { position from an } \\
\text { aromatic ring, or at } \alpha \text { position from a naphthenic ring }\end{array}$ \\
\hline & $32.0-34.5$ & $\mathrm{CH}$ & Methine groups in aliphatic chains \\
\hline & $34.5-42.0$ & $\mathrm{CH}_{2 \alpha, \beta}$ & $\begin{array}{l}\text { Methylene groups branched at } \alpha \text { or } \beta \text { position from an } \\
\text { aromatic ring, or at } \alpha \text { position from a naphthenic ring }\end{array}$ \\
\hline & $42.0-60.0$ & $\mathrm{CH}_{\text {naph }}$ & Methine groups in naphthenic rings \\
\hline \multirow[t]{4}{*}{ Aromatic } & $100-160$ & $C_{a r}$ & \\
\hline & $100-133$ & $C_{b r}, C_{p r}$ & $\begin{array}{l}\text { Bridgehead aromatic carbon, overlapping with } \\
\text { protonated/hetero aromatic carbon }\end{array}$ \\
\hline & $133-150$ & $C_{\text {sub }}$ & Substituted aromatic carbon \\
\hline & $150-160$ & $C_{\text {phen }}$ & Phenolic carbon \\
\hline
\end{tabular}


665 Table 4 AMWs estimated from MWDs using MALDI-TOF in different summation ranges and 666 from 13C NMR spectra

\begin{tabular}{lccccc}
\hline Summation range & \multicolumn{5}{c}{ AMW (Da) } \\
\hline & F1 & F2 & F3 & F4 & Buton \\
$0-1,000 \mathrm{Da}$ & 442 & 474 & 525 & 558 & 541 \\
$0-2,500 \mathrm{Da}$ & 714 & 610 & 709 & 761 & 743 \\
$0-3,000 \mathrm{Da}$ & 898 & 755 & 882 & 957 & 934 \\
AMW estimated from & 1125 & 952 & 1094 & 1204 & 1177 \\
NMR/DEPT & 899 & 717 & 795 & 834 & 795 \\
\hline
\end{tabular}

667

668 